\title{
The Effect of Cigarette Smoke Exposure on Spinal Cord Injury in Rats
}

\author{
Zhong-kai Fan, Yang Cao, Gang Lv, Yan-song Wang, and Zhan-peng Guo
}

\begin{abstract}
In this study, we examined whether cigarette smoke has neuroprotective or toxic effects on spinal cord injury (SCI). Male Sprague-Dawley rats were included in the study and received either cigarette smoke exposure or fresh air exposure. Twenty-four hours after the last cigarette smoke or fresh air exposure, all rats were injured at thoracic level 12 (T12), using an established static compression model. Our data showed that the cigarette smoke group had higher water content; higher permeability of the blood-spinal cord barrier (BSCB); higher malondialdehyde (MDA) levels, aquaporin-4 (AQP4) and hypoxia-inducible factor 1-alpha (HIF-1 $\alpha$ ) protein expression, and mRNA levels; and lower glutathione (GSH) levels than the control group values at $12 \mathrm{~h}, 24 \mathrm{~h}$, and $48 \mathrm{~h}$ after SCI. There was no significant difference in these between the cigarette smoke group and the control group at $0 \mathrm{~h}$ after SCI. The results of the Basso, Beattie, and Bresnahan (BBB) hindlimb locomotor rating scale showed that rats in the cigarette smoke group had greater dysfunction in hindlimb movement than did rats in control group from 2 to day 6 after SCI. The extent of recovery did not make any difference from day 7 to day 10 after SCI between the cigarette smoke group and the control group. These results suggested that cigarette smoke can reinforce the oxidative stress injury via HIF-1 $\alpha$ and AQP4 in the early stage after SCI. It is possible that cigarette smoke exposure does not affect SCI recovery in the long term; however, it can aggravate the edema and deteriorate BSCB disruption via HIF-1 $\alpha$ and AQP4 in the early stage after SCI. More studies will be essential to consider this hypothesis and elucidate the mechanisms involved.
\end{abstract}

Key words: AQP4; cigarette smoke; edema; SCI

\section{Introduction}

$\mathbf{T}$ Here IS NO QUeStion that SMOKING IS HaRmful, affecting most body systems. By now, it is firmly established that smoking is a major risk factor for serious chronic illnesses, including cardiovascular disease, lung disease, and cancer. ${ }^{1}$ The relationship between smoking and neurological diseases has always been controversial. ${ }^{2}$ Smoking is an especially serious health behavior concern for persons with spinal cord injury (SCI), because neurological deficits commonly place them at risk for respiratory problems. ${ }^{3}$ However, there is increasing evidence that smokers have a lower incidence of some inflammatory and neurodegenerative diseases. ${ }^{2,4-9}$ Traumatic injury to the mammalian spinal cord is a highly dynamic process characterized by a complex pattern of pervasive, destructive biochemical and pathophysiological events that limit the potential for functional recovery. ${ }^{10} \mathrm{SCI}$ leads to an inflammatory response that generates substantial secondary damage within the tissue, in addition to the primary damage and severe neurological damage. ${ }^{11}$ However, whether the cigarette smoke has neuroprotective or toxic effects on SCI has not been elucidated.
SCI is invariably associated with spinal cord edema, which accounts for much of the morbidity and mortality of this condition. ${ }^{12}$ Spinal cord edema is often long lasting and therapy resistant. The disruption of the blood-spinal cord barrier (BSCB) after SCI elicits an intensive local inflammation by the infiltration of blood cells such as neutrophils and macrophages, leading to cell death and permanent neurological disability. ${ }^{13}$ One hypothesis is that cigarette smoke can aggravate BSCB disruption and exacerbate SCIinduced edema after SCI. The present study was designed to compare the SCI effect on the spinal cord water content and motor function recovery of rats exposed to cigarette smoke and those not exposed, to further explore the reinforced damage mechanism of cigarette smoke.

Previous studies indicated that the changes in aquaporin-4 (AQP4) expression are associated with spinal cord edema and BSCB permeability. ${ }^{14}$ A recent study reported that changes in AQP4 expression in injured spinal cords paralleled changes in spinal cord water content and reduced spinal cord edema in AQP4null rats after $\mathrm{SCI},{ }^{15,16}$ providing evidence for involvement of AQP4 in SCI-related edema. As AQP4-overexpression is likely triggered by hypoxia, ${ }^{17}$ and cigarette smoke contains a high

Department of Orthopaedics, The First Affiliated Hospital, Liaoning Medical University, Jinzhou, Liaoning Province, China. 
concentration of free radicals and induces oxidative stress in the lung and other tissues, ${ }^{18}$ we hypothesized that cigarette smoke can strengthen the injured damage of SCI by oxidative stress related hypoxia. Malondialdehyde (MDA) and glutathione (GSH) are stable metabolites of the free radical-mediated lipid peroxidation cascade, and important endogenous antioxidants respectively, which are widely used as markers of oxidative stress. These paradigms were designed to mimic the effects of cigarette smoke on the permeability of BSCB, GSH, MDA levels, AQP4, and hypoxiainducible factor 1-alpha (HIF-1 $\alpha$ ) expression after SCI.

\section{Methods}

\section{Cigarette smoke exposure model}

All animal experiments were conducted in accordance with the National Institutes of Health Guide for the Care and Use of Laboratory Animals. The male Sprague-Dawley rats (100-150 g) were purchased from the Experimental Animals Center of China Medical University. The rats were randomly divided into two groups: 1) fresh air exposure (control group); 2) smoke exposure (cigarette smoke group). The rats were exposed to cigarette smoke from commercially available filter cigarettes $(1.3 \mathrm{mg}$ of nicotine and $15 \mathrm{mg}$ of tar) in a plastic chamber $\left(100 \times 70 \times 50 \mathrm{~cm} ; 0.35 \mathrm{~m}^{3}\right)$. Ten rats were put in the chamber and each cigarette was lit from the cigarette end, allowed to freely burn for $15 \mathrm{~min}$, and then the cigarette smoke was allowed to diffuse in the whole chamber for another $25 \mathrm{~min}$. Fresh air inhalation was performed for $10 \mathrm{~min}$ after every $40 \mathrm{~min}$ of sidestream smoke exposure. ${ }^{19,20}$ The rats were repeatedly exposed to the smoke of a total of 10 cigarettes (or fresh air) each day for up to 6 weeks. Total time of smoke exposure was $5 \times 40 \mathrm{~min}=200 \mathrm{~min} /$ day. The rest of the time animals were exposed to fresh air. In the fresh air group, rats were placed in similar chambers and exposed to room air.

\section{Spinal cord compression injury models in rats}

Twenty-four hours after the last cigarette smoke or room air exposure, all rats were injured at the thoracic level 12 (T12), using an established static compression model. ${ }^{21,22}$ The skin and muscle overlying the spinal column were incised and a laminectomy was performed at T12, leaving the dura intact. The compression was applied by suspending the base of the compression platform (area $2 \times 5 \mathrm{~mm}$ ) onto the exposed T12 cord under microscopic control. A weight of $50 \mathrm{~g}$ was applied statically to the platform for exactly $5 \mathrm{~min}$.

\section{Determination of spinal cord water content}

Spinal cord edema was evaluated by determining the water content of the spinal cord. For the time course study, the injured spinal cords for all groups were dried for $48 \mathrm{~h}$ at $80^{\circ} \mathrm{C}$ for determination of the dry weight. Water content in spinal cord tissue was obtained by the following calculations: spinal cord water content $(\%)=($ wet weight - dry weight $) /$ wet weight $\times 100 \%$.

\section{Measurement of BSCB permeability}

The BSCB permeability tracer ${ }^{99 \mathrm{~m}} \mathrm{Tc}$-albumin was used to assess BSCB breakdown, and rats were injected intravenously with $4 \mathrm{MBq}$ of one of the ${ }^{99 \mathrm{~m}} \mathrm{Tc}$-labeled tracers $10 \mathrm{~min}$ before decapitation at $0 \mathrm{~h}$, $12 \mathrm{~h}, 24 \mathrm{~h}$, and $48 \mathrm{~h}$ after SCI. The uptake of ${ }^{99 \mathrm{~m}} \mathrm{Tc}$-albumin in the thoracic spinal cord was measured 10 min after injection.

\section{Grading of motor disturbance}

The motor function of rats subjected to compression trauma was assessed once a day for 10 days after injury. Recovery from motor disturbance was graded using the modified Basso, Beattie, and Bresnahan (BBB) hindlimb locomotor rating scale. ${ }^{23,24}$

\section{Biochemical determination}

Protein carbonyl content, as an index of protein oxidation, was measured by a modification of a previous technique. ${ }^{25}$ The MDA concentration of the homogenates was determined spectrophotometrically by measuring the presence of thiobarbituric acid reactive substances. ${ }^{26}$ Data were presented as $\mathrm{ng} / \mathrm{mg}$ of soluble extracted protein. GSH was determined by the spectrophotometric method, which was based on the use of Ellman's reagent. Results were expressed as $\mathrm{nM} / \mathrm{g}$ tissue.

\section{RNA isolation and reverse transcription polymerase chain reaction ( $R T-P C R)$}

At $0 \mathrm{~h}, 12 \mathrm{~h}, 24 \mathrm{~h}$, and $48 \mathrm{~h}$ after surgery, total RNA from the injured spinal cord was extracted with TRLzol reagent (Invitrogen, USA) and the quality of RNA was analyzed by A260/A280 ratio and gel analysis. The reverse transcription was performed with RNA PCR Kit (AMV Ver.3.0, Takara, Japan) according to the manufacturer's protocols, and cDNAs were generated from $1 \mu \mathrm{g}$ of total RNA from each example. The oligonucleotide primers were as follows: AQP4 (340 bp): 5'-ATC AGC CCT GGC CAC ATC AA$3^{\prime}$ forward) and 5'-TCC AAT TGC AAC AGA AAA CC-3' (reverse); HIF-1 $\alpha$ (210 bp): 5'-TGC TTG GTG CTG ATT TGT GA-3' (forward) and 5'-GGT CAG ATG ATC AGA GTC CA-3' (reverse). (And the reaction was performed for 35 cycles, using a $95^{\circ} \mathrm{C}, 30 \mathrm{sec}$ denaturing step; a $57^{\circ} \mathrm{C}, 30 \mathrm{sec}$ annealing step; and a $72^{\circ} \mathrm{C}, 1 \mathrm{~min}$ extension step. PCR products were electrophoresed on a $2 \%$ agarose gel, and semiquantitative evaluation of their mRNA expression levels was performed relative to expression of the housekeeping gene glyceraldehyde-3-phosphate dehydrogenase (GAPDH). The primers for GAPDH were: forward, 5'-CCA CCC ATG GCA AAT TCC CAT GGC A-3'; and reverse, 5'-TCT AGA CGG CAG GTC AGG TCC ACC-3’'

\section{Western blot analysis}

Western blot analysis was performed to investigate the protein expression of AQP4 and HIF-1 $\alpha$, which was extracted at $0 \mathrm{~h}, 12 \mathrm{~h}$, $24 \mathrm{~h}$, and $48 \mathrm{~h}$ after SCI at the injured spinal cord. The cord samples were sonicated in ice-cold lysis buffer $(2 \mathrm{mM}$ ethylenediaminetetraacetic acid [EDTA], $10 \mathrm{mM}$ ethylene glycol tetraacetic acid [EGTA], $0.4 \% \mathrm{NaF}, 20 \mathrm{mM}$ Tris- $\mathrm{HCl}$, and protease inhibitors, $\mathrm{pH}$ 7.5). The protein concentration of soluble materials was determined by the Coomassie $\mathrm{G} 250$ binding method. The protein lysates ( $25 \mu \mathrm{g}$ per lane for each sample) were fractioned on $12 \%$ sodium dodecyl sulfate (SDS)-polyacrylamide gels, followed by transferring to polyvinylidene fluoride membranes. The membranes were blocked with 5\% skimmed milk Tween phosphate-buffered saline (PBS) to block nonspecific binding sites. The blots were then incubated with rabbit polyclonal antibody anti-AQP4 (dilution 1:400; Santa Cruz Biotechnology, Inc.), HIF-1 $\alpha$ (dilution 1:200; Santa Cruz Biotechnology, Inc.) or $\beta$-actin (Zhongshan Golden Bridge Biotechnology, 1:1000) overnight at $4^{\circ} \mathrm{C}$ and followed by each corresponding second antibody at room temperature for $1 \mathrm{~h}$ at $37^{\circ} \mathrm{C}$. Then, the results were developed by ECL (Pierce Biotechnology, USA). The protein bands were then analyzed using the BioImageing System (UVP, USA). The gray scale value of AQP4 and HIF- $1 \alpha$ was normalized to the values of the corresponding $\beta$-actin band to determine the expression level of the protein. The experiments were repeated at least three times independently.

\section{Data collection and statistical analysis}

Two trained observers, blinded to experiment condition, worked in conjunction with the experimenters who had conducted the 
experimental session to weigh and code the experimental data. However, if there was a discrepancy in individual scores, both observers reevaluated together by reaching a consensus agreement before combining the individual scores. SPSS version 13.0 for Windows was used for all analyses. Data values were expressed as means \pm SD. Differences between the groups were statistically evaluated by one way ANOVA with a Student-Newman-Keuls test and two way repeated measures ANOVA for multiple comparisons, or Student's $t$ test for comparison between two groups. $p<0.05$ was considered statistically significant. All reported $p$ values are two sided.

\section{Results}

\section{Effect on water content of spinal cord}

Cigarette smoke resulted in higher water content when compared with unexposed controls at $12 \mathrm{~h}, 24 \mathrm{~h}$, and $48 \mathrm{~h}$ after SCI $(84.91 \pm 0.40 \%$ vs. $82.86 \pm 0.37 \%, 85.44 \pm 0.28 \%$ vs. $82.57 \pm 0.40 \%$, and $84.11 \pm 0.16 \%$ vs. $82.42 \pm 0.42 \%$, respectively, $p<0.05$, Fig. 1 ). However, there was no significant difference in water content between the cigarette smoke group and the control group at $0 \mathrm{~h}$ after SCI $(76.99 \pm 0.28 \%$ vs. $77.14 \pm 0.31 \%, p>0.05$, Fig. 1$)$.

\section{Effect on the permeability of BSCB}

To determine whether cigarette smoke aggravated the permeability increase of BSCB induced by SCI, the content of ${ }^{99 \mathrm{~m}} \mathrm{Tc}$ albumin in the injured spinal cord tissue was measured. Our results revealed that the content of ${ }^{99 \mathrm{~m}} \mathrm{Tc}$-Albumin in spinal cord tissue of cigarette smoke group was significantly higher $(49.9 \pm 2.7 \mu \mathrm{L} / \mathrm{g}$, $59.5 \pm 2.1 \mu \mathrm{L} / \mathrm{g}$ and $60.1 \pm 2.6 \mu \mathrm{L} / \mathrm{g}$ ) than that in the control group $(42.1 \pm 3.2 \mu \mathrm{L} / \mathrm{g}, 52.3 \pm 4.1 \mu \mathrm{L} / \mathrm{g}$ and $55.6 \pm 2.8 \mu \mathrm{L} / \mathrm{g})$ at $12 \mathrm{~h}, 24 \mathrm{~h}$ and $48 \mathrm{~h}$ after SCI, respectively (Fig. 2). There was no significant difference between the cigarette smoke group and the control group at $0 \mathrm{~h}$ after SCI (12.2 \pm 3.7 vs. $10.7 \pm 5.1, p>0.05$, Fig. 2).

\section{Effect on motor functions of rats}

The results of BBB hindlimb locomotor rating scale showed that rats in the cigarette smoke group had greater dysfunction in hin-

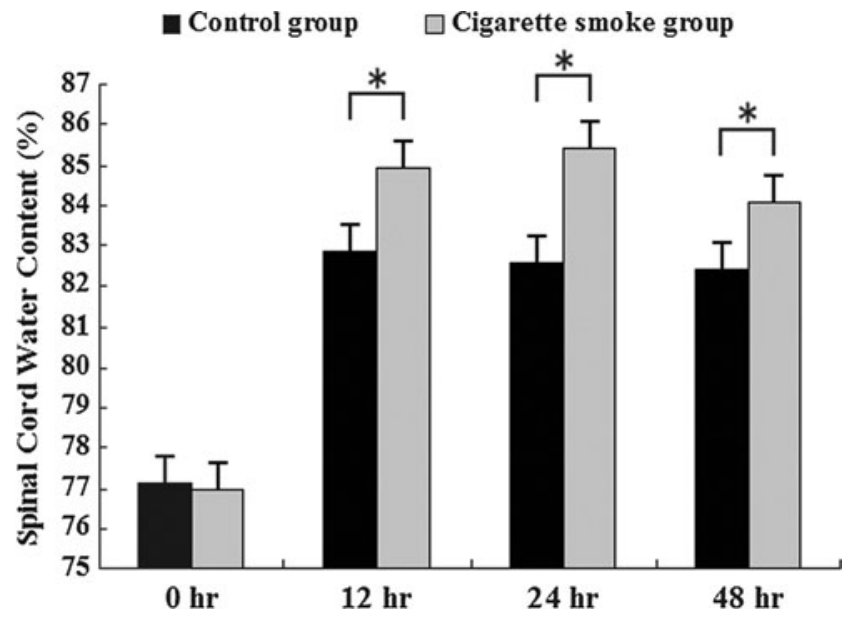

FIG. 1. Changes in percentage of water content in the injured spinal cord areas of the cigarette smoke group and the control group at different time points after spinal cord injury (SCI). The data are represented as mean $\pm \mathrm{SD}\left(n=5\right.$, each). ${ }^{*} p<0.05$ versus control group by $t$ test.

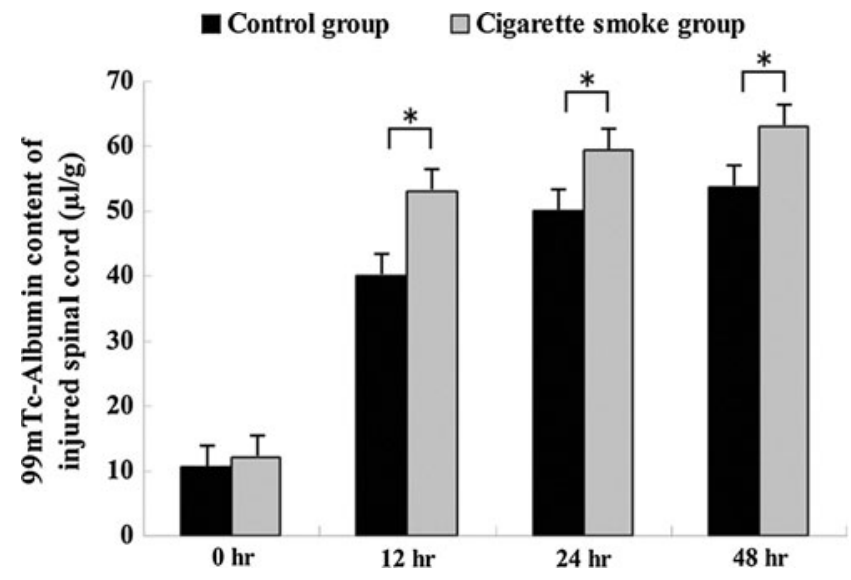

FIG. 2. The effect of cigarette smoke exposure on the permeability increase of the blood-spinal cord barrier (BSCB) induced by spinal cord injury (SCI) at different time points after SCI. Increased permeability of the injured spinal cord to ${ }^{99 \mathrm{~m}} \mathrm{Tc}$-albumin at $12 \mathrm{~h}, 24 \mathrm{~h}$, and $48 \mathrm{~h}$ after SCI. Data represent mean \pm SD $\left(n=5\right.$, each). ${ }^{*} p<0.05$ versus control group by $t$ test.

dlimb movement than did rats in the control group from 2 to day 6 after SCI (Fig. 3).

\section{Effect on MDA and GSH levels of injured spinal cord}

MDA levels in the cigarette smoke group were significantly higher than in the control group at $12 \mathrm{~h}, 24 \mathrm{~h}$ and $48 \mathrm{~h}$ after SCI (Fig. 4). And GSH levels were lower in the cigarette smoke group than in the control group at $12 \mathrm{~h}, 24 \mathrm{~h}$ and $48 \mathrm{~h}$ after SCI (Fig. 5). However, there was no significant difference in MDA and GSH levels between the cigarette smoke group and the control group at $0 \mathrm{~h}$ after SCI (Figs. 4 and 5).

\section{Effect on the expression HIF-1 $\alpha$ and AQP4 protein}

Our results showed that AQP4 and HIF- $1 \alpha$ protein expression and mRNA levels were found quite weak in the injured spinal cord of rats at $0 \mathrm{~h}$ after SCI. AQP4 and HIF- $1 \alpha$ levels were increased in the spinal cord tissues from all the rats at $12 \mathrm{~h}, 24 \mathrm{~h}$ and $48 \mathrm{~h}$ after SCI, and the expression of AQP4 and HIF- $1 \alpha$ was significant higher in the cigarette smoke group than in the control group at $12 \mathrm{~h}, 24 \mathrm{~h}$ and $48 \mathrm{~h}$ after SCI. The results of RT-PCR and Western blotting showed the upregulation of AQP4 protein expression and mRNA after the treatment of cigarette smoke $(p<0.05$, Fig. 6$)$.

\section{Discussion}

The relationship between smoking and neurological diseases has always been controversial. Cigarette smoke is the leading cause of preventable diseases worldwide. It is associated with an increased incidence of diseases including acute respiratory infections, periodontitis, bacterial meningitis, rheumatoid arthritis, Crohn's disease, systemic lupus erythematosus, atherosclerosis, chronic obstructive pulmonary diseases, lung cancer, and coronary heart disease. $^{27}$ On the other hand, increasingly, data indicate that smoking can decrease the incidence and/or severity of several diseases, including ulcerative colitis, Parkinson's disease (PD), some forms of Alzheimer's disease (AD), hypersensitivity pneumonitis (HP), and others. It needs to be determined what effect cigarette smoke has on SCI and whether it is neuroprotective or toxic. No other research offers insight into this. 


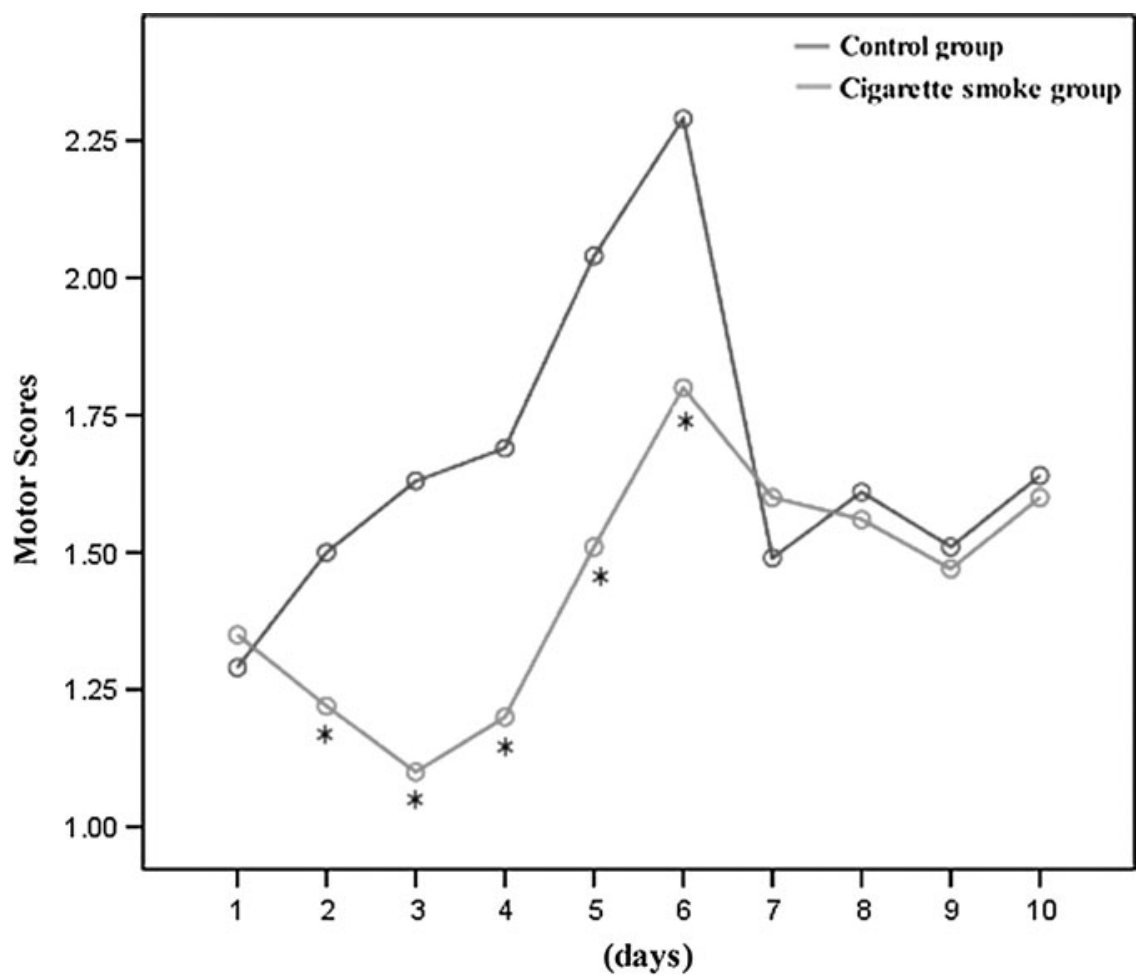

FIG. 3. The degree of motor disturbance was assessed every day until 10 days after spinal cord injury (SCI) by Basso, Beattie, and Bresnahan (BBB) criteria. The differences of BBB hindlimb locomotor rating scale between the cigarette smoke group and the control group were examined using two way repeated measures ANOVA. The rats in the cigarette smoke group had greater dysfunction in hindlimb movement than did rats in the control group from day 2 to day 6 after SCI. There was no difference in the extent of recovery from day 7 to day 10 after SCI between the cigarette smoke group and the control group. Data represent means \pm SD ( $n=10$, each). $* p<0.05$ versus control group by repeated measures ANOVA.

In the present study, we conducted a comparative analysis of both cigarette smoke exposed and unexposed rats to determine the effect of cigarette smoke on SCI. We demonstrated that cigarette smoke exposure resulted in higher water content, permeability of BSCB, AQP4 and HIF- $1 \alpha$ protein expression, and mRNA levels

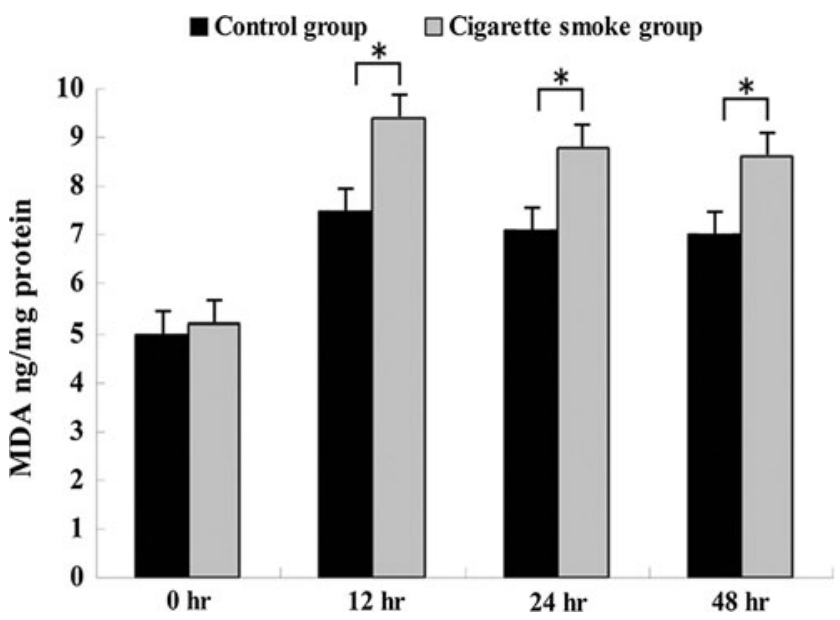

FIG. 4. Effects of cigarette smoke exposure on the injured spinal cord malondialdehyde (MDA) levels in the cigarette smoke group were significantly higher than in control group at $12 \mathrm{~h}, 24 \mathrm{~h}$, and $48 \mathrm{~h}$ after spinal cord injury (SCI). However, there was no significant difference in MDA levels between the cigarette smoke group and the control group at $0 \mathrm{~h}$ after SCI. Data represent means $\pm \mathrm{SD}(n=5$, each). $* p<0.05$ versus control group by $t$ test. after SCI at $12 \mathrm{~h}, 24 \mathrm{~h}$, and $48 \mathrm{~h}$ after SCI. No significant difference on these was seen between cigarette smoke exposed group and the control group at $0 \mathrm{~h}$ after SCI.

Oxidative stress can lead to the production of reactive oxygen species (ROS), which are a family of molecules that includes highly reactive free oxygen radicals (e.g., superoxide anion $\left[\mathrm{O}_{2} \cdot{ }^{-}\right]$and the

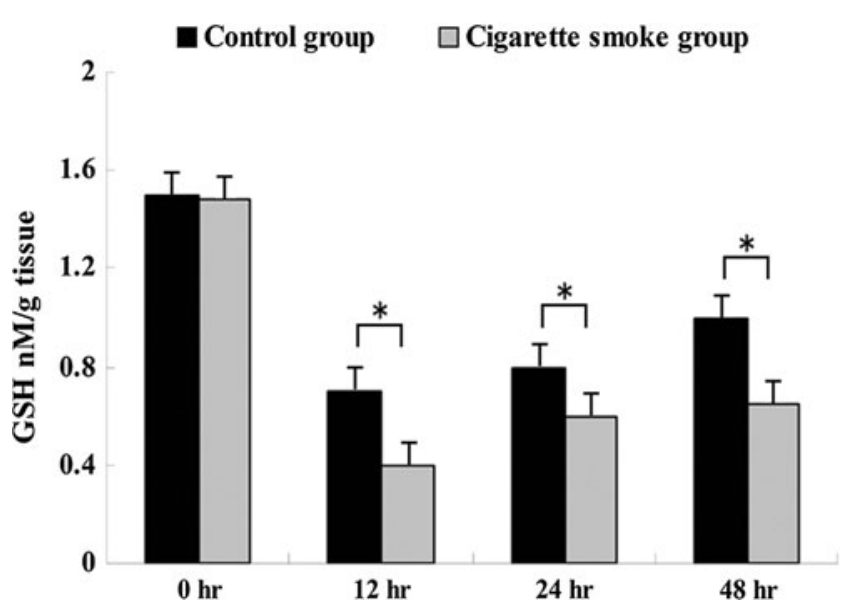

FIG. 5. Changes in the glutathione (GSH) levels of the injured spinal cord in the cigarette smoke group and the control group at different time points after spinal cord injury (SCI). GSH levels were lower in the cigarette smoke group than in the control group at $12 \mathrm{~h}, 24 \mathrm{~h}$, and $48 \mathrm{~h}$ after SCI. Data represent means \pm SD $(n=5$, each). $* p<0.05$ versus control group by $t$ test. 

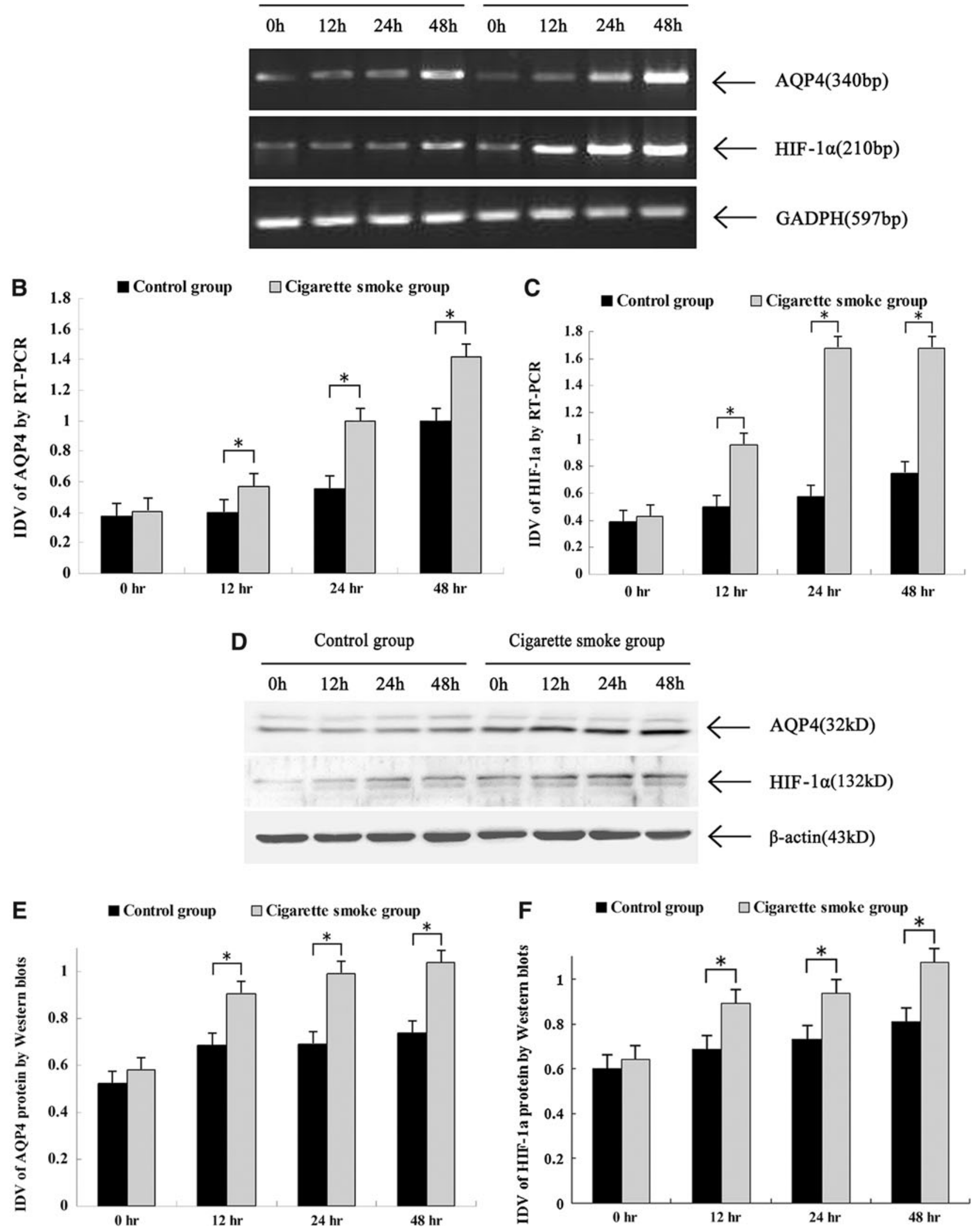

FIG. 6. Effects of cigarette smoke exposure on aquaporin-4 (AQP4) and hypoxia-inducible factor 1-alpha (HIF-1 $\alpha$ ) protein expression and mRNA levels. Representative Western blots illustrating difference in the bands of AQP4 and HIF- $1 \alpha$, respectively (A). Relative integrated density value (IDV) analysis of AQP4 (B) and HIF- $1 \alpha(\mathbf{C}) .{ }^{*} p<0.05$ versus control group by $t$ test. Representative reverse transcription polymerase chain reaction (RT-PCR) illustrating differences in the $340 \mathrm{bp}$ band of AQP4 and the $210 \mathrm{bp}$ band of HIF-1 $\alpha$ mRNA, respectively (D). Relative IDV analysis of AQP4 mRNA (E) and HIF-1 $\alpha$ mRNA (F). * $p<0.05$ versus control group by $t$ test. 
hydroxyl radical $\left.\left[\mathrm{OH}^{-}\right]\right)$and the stable "diffusible""non-radical oxidants (e.g., hydrogen peroxide $\left[\mathrm{H}_{2} \mathrm{O}_{2}\right]$ ), recognized as dangerous second messengers in many mechanisms. ${ }^{28,29}$ It has been suggested that ROS and oxidative stress have a significant role in the pathophysiology of SCI, and that alleviating oxidative stress is an effective strategy for therapeutic intervention of SCI. ${ }^{30}$ Cigarette smoke exposure resulted in oxidative stress because of the direct effects of the radicals present in smoke. ${ }^{31,32}$ Our study demonstrated that MDA levels were significantly lower and that GSH levels were higher in the cigarette smoke group than in the control group at $12 \mathrm{~h}, 24 \mathrm{~h}$, and $48 \mathrm{~h}$ after SCI. HIF- $1 \alpha$ is a nuclear transcription factor and is critical for initiating cellular response to hypoxia. Many studies demonstrated that there was a very close relationship between the expression of HIF- $1 \alpha$ and the formation of ROS. ${ }^{33}$ The research on the smokers with primary spontaneous pneumothorax showed that cigarette smoke exposure can result in lung macrophage oxidative stress via the HIF- $1 \alpha$ pathway. ${ }^{34}$ This can explain why cigarette smoke exposure can upregulate HIF- $1 \alpha$ expression at $12 \mathrm{~h}, 24 \mathrm{~h}$, and $48 \mathrm{~h}$ after SCI. It is suggested that cigarette smoke exposure can reinforce oxidative stress injury via HIF- $1 \alpha$ after SCI.

AQP4 is a water channel protein expressed in glial cells of spinal cord. ${ }^{35}$ Previous studies have shown a remarkably improved clinical and histological outcome in AQP4 ${ }^{-/-}$mice following SCI, which was explicable by reduced spinal cord edema. High AQP4 expression in injured spinal cords paralleled changes in spinal cord water content. ${ }^{16}$ As a result of a large abundance of AQP4-overexpressing astrocytes in SCI rats, overall AQP4 levels were significantly and persistently increased by several fold, not only at the mRNA, but also at the protein level. ${ }^{15} \mathrm{~A}$ recent study in rats demonstrated that under hypoxic conditions, upregulation of HIF$1 \alpha$ was associated with AQP4 increase in the brain, and that HIF- $1 \alpha$ inhibitor can benefit neurological outcomes by reducing water content or brain swelling rates with downregulation of AQP4. ${ }^{36-38}$ Cigarette smoke exposure can upregulate water content and AQP4 expression, which is likely triggered by HIF- $1 \alpha$.

It is difficult to explain why the water content, permeability of BSCB, AQP4 and HIF- $1 \alpha$ protein expression, and mRNA levels in the cigarette smoke group did not show a significant difference compared with the control group at $0 \mathrm{~h}$ after SCI. Few data are available concerning this. We think that the BSCB plays an important role. As an interface between the spinal cord and the periphery, BSCB constitutes a physical/biochemical barrier between the central nervous system (CNS) and the systemic circulation, which serves to protect the microenvironment of the spinal cord. Once SCI occurs, the integrity of the BSCB disrupts, and a series of pathophysiological changes emerges. Because the time interval is so short, we cannot detect the changes in water content, permeability of BSCB, and AQP4 and HIF- $1 \alpha$ expression. Therefore, our findings indicate that cigarette smoke can reinforce the oxidative stress injury via HIF- $1 \alpha$ and AQP4 in the early stage after SCI.

The results of the BBB hindlimb locomotor rating scale showed that rats in the cigarette smoke group had greater dysfunction in hindlimb movement than did the rats in the control group from day 2 to day 6 after SCI. The extent of recovery did not make any difference from 7 to day 10 after SCI between the cigarette smoke group and control group. This may because of the compensating function of the rat recovery after SCI. We hypothesize that maybe in terms of long-term recovery, cigarette smoke exposure cannot affect recovery after SCI, but it can aggravate the edema and deteriorate the BSCB disruption via HIF- $1 \alpha$ and AQP4 in the early stage after SCI. More studies will be essential to consider this hypothesis and elucidate the mechanism involved in it.

\section{Acknowledgments}

This study was supported by Scientific Research Foundation for the Doctoral Program, Ministry of Science and Technology, Liaoning Province (No.20121094) and National Natural Science Foundation of China (No. 81101421 and 81272074).

\section{Author Disclosure Statement}

No competing financial interests exist.

\section{References}

1. Fleischer, N.L., Roux, A.V., and Hubbard, A.E. (2012). Inequalities in body mass index and smoking behavior in 70 countries: evidence for a social transition in chronic disease risk. Am. J. Epidemiol. 175, 167-176.

2. Fratiglioni, L., and Wang, H.X. (2000). Smoking and Parkinson's and Alzheimer's disease: review of the epidemiological studies. Behav. Brain Res. 113, 117-120.

3. Weaver, F.M., Smith, B., LaVela, S.L., Evans, C.T., Ullrich, P., Miskevics, S., Goldstein, B., Strayer, J., and Burns, S.P. (2011). Smoking behavior and delivery of evidence-based care for veterans with spinal cord injuries and disorders. J. Spinal Cord Med. 34, 35-45.

4. Decina, P., Caracci, G., Sandik, R., Berman, W., Mukherjee, S., and Scapicchio, P. (1990). Cigarette smoking and neuroleptic-induced parkinsonism. Biol. Psychiatry 28, 502-508.

5. Gahring, L.C., and Rogers, S.W. (2006). Neuronal nicotinic acetylcholine receptor expression and function on nonneuronal cells. AAPS J. 7, E885-894.

6. Huang, L.Z., Campos, C., Ly, J., Ivy, Carroll. F., and Quik, M. (2011). Nicotinic receptor agonists decrease L-dopa-induced dyskinesias most effectively in partially lesioned parkinsonian rats. Neuropharmacology 60, 861-868.

7. Quik, M., Huang, L.Z., Parameswaran, N., Bordia, T., Campos, C., and Perez, X.A. (2009). Multiple roles for nicotine in Parkinson's disease. Biochem Pharmacol. 78, 677-685.

8. Quik, M., Bordia, T., Huang, L., and Perez, X. (2011). Targeting nicotinic receptors for Parkinson's disease therapy. CNS Neurol. Disord. Drug Targets 10, 651-658.

9. Sabbagh, M.N., Lukas, R.J., Sparks, D.L., and Reid, R.T. (2002). The nicotinic acetylcholine receptor, smoking, and Alzheimer's disease. J Alzheimers Dis. 4, 317-325.

10. McEwen, M.L., Sullivan, P.G., Rabchevsky, A.G., and Springer, J.E. (2011). Targeting mitochondrial function for the treatment of acute spinal cord injury. Neurotherapeutics $8,168-179$.

11. Erşahin, M., Toklu, H.Z. Erzik, C., Akakin, D., Tetik, S., Sener, G., Yeğen, B.C. (2011). Ghrelin alleviates spinal cord injury in rats via its anti-inflammatory effects. Turk. Neurosurg. 21, 599-605.

12. Goldberg, A.L., and Kershah, S.M. (2010). Advances in imaging of vertebral and spinal cord injury. J. Spinal Cord Med. 33, 105-116.

13. Lee, J.Y., Kim, H.S., Choi, H.Y., Oh, T.H., Ju, B.G., and Yune, T.Y. (2012). Valproic acid attenuates blood-spinal cord barrier disruption by inhibiting matrix metalloprotease- -9 activity and improves functional recovery after spinal cord injury. J Neurochem. 121, 818-829.

14. Xu, W.B., Gu, Y.T., Wang, Y.F., Lu, X.H., Jia, L.S., and Lv, G. (2008). Bradykinin preconditioning modulates aquaporin-4 expression after spinal cord ischemic injury in rats. Brain Res. 1246, 11-18.

15. Nesic, O., Lee, J., Ye, Z., Unabia, G.C., Rafati, D., Hulsebosch, C.E., and Perez-Polo, J.R. (2006). Acute and chronic changes in aquaporin 4 expression after spinal cord injury. Neuroscience 143, 779-792.

16. Saadoun, S., Bell, B.A., Verkman, A.S., and Papadopoulos, M.C. (2008). Greatly improved neurological outcome after spinal cord compression injury in AQP4-deficient mice. Brain 131, 1087-1098.

17. Nesic, O., Guest, J.D., Zivadinovic, D., Narayana, P.A., Herrera, J.J., Grill, R.J., Mokkapati, V.U., Gelman, B.B., and Lee, J. (2010). Aquaporins in spinal cord injury: the janus face of aquaporin 4. Neuroscience 168, 1019-1035.

18. Tharappel, J.C., Cholewa, J., Espandiari, P., Spear, B.T., Gairola, C.G., and Glauert, H.P. (2010). Effects of cigarette smoke on the activation of oxidative stress-related transcription factors in female A/J mouse lung. J. Toxicol. Environ. Health A. 73, 1288-1297. 
19. Lei, Y., Cao Y, X., Xu, C.B., and Zhang, Y. (2008). The Raf-1 inhibitor GW5074 and dexamethasone suppress sidestream smokeinduced airway hyperresponsiveness in mice. Respir Res. 9, 71.

20. Cao, L., Zhang, Y., Cao, Y.X., Edvinsson, L., and Xu, C.B. (2010), Cigarette smoke upregulates rat coronary artery endothelin receptors in vivo. PLoS One 7, e33008.

21. Huang, W.L., George, K.J., Ibba, V., Liu, M.C., Averill, S., Quartu, M., Hamlyn, P.J., and Priestley, J.V. (2007). The characteristics of neuronal injury in a static compression model of spinal cord injury in adult rats. Eur. J. Neurosci. 25, 362-372.

22. McEwen, M.L., Sullivan, P.G., and Springer, J.E. (2007). Pretreatment with the cyclosporine derivative, NIM811, improves the function of synaptic mitochondria following spinal cord contusion in rats. J. Neurotrauma 24, 613-624.

23. Basso, D.M., Beattie, M.S., and Bresnahan, J.C. (1995). A sensitive and reliable locomotor rating scale for open field testing in rats. J. Neurotrauma 12, 1-21.

24. Joshi, M., and Fehlings, M.G. (2002). Development and characterization of a novel, graded model of clip compressive spinal cord injury in the mouse: Part 2. Quantitative neuroanatomical assessment and analysis of the relationships between axonal tracts, residual tissue, and locomotor recovery. J. Neurotrauma 19, 191-203.

25. Levine, R.L., Williams, J.A., Stadtman, E.R., and Shacter, E. (1994). Carbonyl assays for determination of oxidatively modified proteins. Methods Enzymol. 233, 346-357.

26. Vermeulen, N.P., and Baldew, G.S. (1992). The role of lipid peroxidation in the nephrotoxicity of cisplatin. Biochem Pharmacol. 44, 1193-1199.

27. Piao, W.H., Campagnolo, D., Dayao, C., Lukas, R.J., Wu, J., and Shi, F.D. (2009). Nicotine and inflammatory neurological disorders. Acta Pharmacol Sin. 30, 715-722.

28. Chen, Y.T., Sun, C.K., Lin, Y.C., Chang, L.T., Chen, Y.L., Tsai, T.H., Chung, S.Y., Chua, S., Kao, Y.H., Yen, C.H., Shao, P.L., Chang, K.C., Leu, S., and Yip, H.K. (2011). Adipose-derived mesenchymal stem cell protects kidneys against ischemia-reperfusion injury through suppressing oxidative stress and inflammatory reaction. J Transl Med. 9, 51.

29. Gough, D.R., and Cotter, T.G. (2011). Hydrogen peroxide: a Jekyll and Hyde signalling molecule. Cell Death Dis. 2, e213.

30. Jia, Z., Zhu, H., Li, J., Wang, X., Misra, H., and Li, Y. (2011). Oxidative stress in spinal cord injury and antioxidant-based intervention. Spinal Cord 50, 264-274.

31. Valenti, V.E., de Abreu, L.C., Sato, M.A., Ferreira, C., Adami, F., Fonseca, F.L., Xavier, V., Godoy, M., Monteiro, C.B., Vanderlei,
L.C., and Saldiva, P.H. (2012). Sidestream cigarette smoke effects on cardiovascular responses in conscious rats: involvement of oxidative stress in the fourth cerebral ventricle. BMC Cardiovasc Disord. 12, 22.

32. Sun, W., Chang, S.S., Fu, Y., Liu, Y., and Califano, J.A. (2011). Chronic CSE treatment induces the growth of normal oral keratinocytes via PDK2 upregulation, increased glycolysis and HIF1 $\alpha$ stabilization. PLoS One 6, e16207.

33. Qutub, A.A., and Popel, A.S. (2008). Reactive oxygen species regulate hypoxia-inducible factor 1alpha differentially in cancer and ischemia. Mol. Cell Biol. 28, 5106-5119.

34. Goven, D., Boutten, A., Leçon-Malas, V., Marchal-Sommé, J., Soler, P., Boczkowski, J., and Bonay, M. (2010). Induction of heme oxygenase -1 , biliverdin reductase and $\mathrm{H}$-ferritin in lung macrophage in smokers with primary spontaneous pneumothorax: role of HIF-1alpha. PLoS One 5, e10886.

35. Oshio, K., Binder, D.K., Yang, B., Schecter, S., Verkman, A.S., and Manley, G.T. (2004). Expression of aquaporin water channels in mouse spinal cord. Neuroscience 127, 685-693.

36. Ding, J.Y., Kreipke, C.W., Speirs, S.L., Schafer, P., Schafer, S., and Rafols, J.A. (2009). Hypoxia-inducible factor-1alpha signaling in aquaporin upregulation after traumatic brain injury. Neurosci. Lett. $453,68-72$.

37. Higashida, T., Peng, C., Li, J., Dornbos, D. 3rd., Teng, K., Li, X., Kinni, H., Guthikonda, M., and Ding, Y. (2011). Hypoxia-inducible factor- $1 \alpha$ contributes to brain edema after stroke by regulating aquaporins and glycerol distribution in brain. Curr. Neurovasc. Res. 8, 44-51.

38. Kaur, C., Sivakumar, V., Zhang, Y., and Ling, E.A. (2006). Hypoxiainduced astrocytic reaction and increased vascular permeability in the rat cerebellum. Glia 54, 826-839.

Address correspondence to: Zhong-kai Fan, MD Department of Orthopaedics The First Affiliated Hospital

Liaoning Medical University

5-2 Renming Street, Guta District Jinzhou 121000, Liaoning Province

China

E-mail: fanzk_ln@126.com 